\title{
Sustainability and Economic Attributes of Peer-To-Peer Accommodation: A Cross Country Perception of Asian Tourists
}

\author{
DOI 10.18267/pr.2021.krn.4816.16
}

\author{
Mark Ratilla ${ }^{1}$ - Sandeep Dey ${ }^{2}$ - Harry Jay Cavite ${ }^{3}$ - Therese Ratilla ${ }^{4}$ - \\ Miloslava Chovancová 5 \\ ORCID iD: 0000-0002-8318-505X ${ }^{1}$, 0000-0002-9103-5422², 0000-0001-8308-91163, \\ 0000-0001-5838-4463 ${ }^{4}, 0000-0002-9244-9563^{5}$ \\ ratilla@utb.cz, dey@utb.cz,62604004@kmitl.ac.th, therese.ratilla@vsu.edu.ph, \\ chovancova@utb.cz \\ 1, 2, 5 Tomas Bata University in Zlin, Faculty of Management and Economics, \\ Zlín, Czech Republic \\ ${ }^{3}$ King Mongkut's Institute of Technology Ladkrabang, Faculty of Agricultural \\ Technology, \\ Bangkok, Thailand \\ ${ }^{4}$ Visayas State University, Visayas Socio-economic Research and Data Analytics \\ Center, \\ Baybay City, Philippines
}

\begin{abstract}
Peer-to-peer (P2P) accommodation has expanded the range of offerings in the tourism and hospitality sector. The study explores the familiarity, usage and overall perception towards P2P accommodation among tourists in the Philippines, Thailand and India. It investigates the association among perceived economic benefits, environmental sustainability and socio-demographic characteristics on tourists' overall perception. A web-based survey was deployed in the first quarter of 2020, right in the onset of Covid-19 pandemic. As the travel frequency of tourists cannot be initially ascertained and to capture their usage in the "normal" times, a recall query with respect to their usage over the past six months (June-December 2019) was utilized. Descriptive statistics and non-parametric statistical tests were employed for data analysis. The findings reveal that the familiarity of Thai tourists lags behind other nationalities. Majority have not used P2P accommodation for the past six months; however, overall perceptions remain positive for both active and non-active users. Across nationalities, respondents somewhat agreed on the nuance of economic benefits and environmental sustainability. Moreover, analysis shows its significant positive association with tourists' overall perception.
\end{abstract}

Keywords: Asia, collaborative consumption, peer-to-peer accommodation, perceptions, sharing economy, sustainability

JEL Classification codes: M30, M31, D16

\section{INTRODUCTION}

The concept of peer-to-peer (P2P) accommodation emerge as individuals offer their spare living spaces (i.e. private or shared room, entire apartment or house) to others in digital platforms usually in exchange for money. It is a leading sector in the realm of "sharing economy", a term associated with the phenomenon of sharing underutilized resources in online platforms with a possibility of monetary exchange (Frenken et al., 2014). Apparently, its 
popularity has been elevated by Airbnb, the largest global player in P2P accommodation. Since its launching in 2008, growth has accelerated in a few years. It received 500,000 guests in 2011 and eventually captured 4 million guests in 2013 (PriceWaterhouseCoopers, 2015a). Recently, it has over 7 million accommodation listings and has received over 750 million guest arrivals around the globe since its establishment (Airbnb, 2020). Concurrently, data shows that P2P accommodation shares $7 \%$ of the total worldwide accommodation and is projected to grow by $31 \%$ in 2025 , surpassing the growth rates of traditional lodging options (Bakker \& Twining-Ward, 2018).

Guttentag et al. (2018) and Young et al. (2017) stipulate that the innovative P2P accommodation offering poses disruptions in tourism accommodation industry as it contends with traditional hotel stays. Chen \& Chang (2018) note that this is attributable to its affordability in comparison with other lodging alternatives (hotels) which considerably attracts backpackers and/or economy travelers. Above all, it shares the mainstream promises of the sharing economy on its potential contribution to environmental sustainability and sustainable consumption (Retamal \& Dominish, 2017). All these have stirred the attention of academic researchers, industry practitioners and policy makers as well.

Research studies on P2P accommodation phenomenon have been increasing (Belarmino \& Koh, 2020; Medina-Hernandez et al., 2020; Prayag \& Ozanne, 2018). A number of them intend to capture the complexities of consumers behavior, specifically on the determinants of consumer choice, intention, and usage of P2P accommodation (Amaro et al., 2019; Guttentag et al., 2018; Mahadevan, 2018; Pappas, 2017; Tussyadiah \& Park, 2018; Yan et al., 2019; Young et al., 2017). Nevertheless, these studies largely focused on consumers in developed countries. This corroborates to the contentions of Retamal \& Dominish (2017) that sharing economy literature is mostly represented in advanced economy context as most people have ample amounts of resources and can readily share these with others. The authors further remark that the sharing economy can be viewed differently in the developing world, specifically on easing the access of previously inaccessible resources. Hossain (2020) recent comprehensive review on sharing economy likewise suggests to carry-out investigation in developing countries to balance insights pertaining to the novel phenomenon. Moreover, stress that the growth rate of P2P accommodation is maturing in advanced economies, while, expansion is seen in the emerging markets (Bakker \& Twining-Ward, 2018).

Given these, the study sets out an exploratory investigation on the familiarity, usage and overall perception towards P2P accommodation among tourists from emerging countries in Asia. The study was conducted in The Philippines, Thailand, and India due to their developing tourism industry as vouched by domestic tourism expansion and substantial international tourist arrivals. Furthermore, owing to the popular view on the economic benefits and sustainability impacts of P2P accommodation and the sharing economy as a whole, the study explicitly initiates a cross-country comparison of tourists' perceptions upon the aforementioned views. The association of perceived economic benefits, environmental sustainability, and sociodemographic characteristics on tourists overall positive perception was also investigated.

The study, therefore, offers initial insights on tourists' behavior towards P2P accommodation in the selected tourism hubs in Asia. Given the existing geographic and cultural differences of subjects, findings to some extent ascertain the ubiquity of economic benefits and environmental sustainability perceptions towards P2P accommodation and its association with tourists overall positive perceptions. Meanwhile, as positive perception about a product or service offering is integral to every purchase decision (Nam et al., 2017; Wee et al., 2014), the study provides insights to service and platform providers of P2P accommodation in designing effective business strategies. 


\section{LITERATURE REVIEW}

Over the years, the development of the sharing economy has considerably caught the attention of various stakeholders including those from the academia. The concept is basically founded on an age-old practice of sharing which is an inherent activity since human existence (Belk, 2010). However, advances in technology (i.e. Internet and Web 2.0) have expanded and hastened sharing activities between people (Belk, 2014). Frenken et al. (2014) note that a clear-cut definition of the term "sharing economy" remains to be non-existent in literature. Nevertheless, it can be distinguished by stressing on access-based over ownership-based consumption of underutilized resources between consumers in digital platforms (Frenken et al., 2014; Habibi et al., 2017). For this reason, the term is also analogously associated with collaborative consumption, peer-to-peer sharing and gig economy (Codagnone \& Martens, 2016). This means that any activities where individuals are temporarily sharing-in and sharingout idle assets (e.g. spare accommodation, transportation, household goods, etc.) to other people via digital platforms are governed within realm of the sharing economy. Therefore, peer-to-peer accommodation as the central discourse in this study falls within this concept.

$\mathrm{P} 2 \mathrm{P}$ accommodation is found to attract a specific generational cohort of consumers - the "millennials" (i.e. born 1980s to 2000s) (Bakker \& Twining-Ward, 2018). PriceWaterhouseCoopers (2015b) indicate that millennial consumers perceived the economic benefits and environmental impacts of the sharing economy. Similarly, Hwang \& Griffiths (2017) describe that they manifest greater awareness on societal and environmental issues, thus, supporting the trend of access-based consumption. Šiuškaite et al. (2019) explain that these perceptions are induced by their education and exposure to advances in technology at early age. Aside from age, Buda et al. (2019) assert the importance of other socio-demographic variables (e.g. income, marital status, education, type of residential settlement) on consumers' receptivity towards sharing economy.

Moreover, as consumer participation in peer-to-peer accommodation continues to exhibit an upward trend, many researchers carried-out studies aiming to understand the consumers' perspective and the key drivers for their participation and/or usage. Indeed, the recent review findings of Belarmino \& Koh (2020) on P2P accommodation pinpoint the vast majority of consumer behavior related studies. Past investigations found that consumers choice for accommodation stay is influenced by a number of factors. However, the framing of affordability makes a predominant appeal to consumers (Guttentag et al., 2018; Möhlmann, 2015; Tussyadiah, 2015). Likewise, Yan et al. (2019) claim that the opportunity for cost savings influence the switching behavior of consumers from booking hotel accommodation to P2P accommodation. Moreover, Pappas (2017) highlights the significance of pricing sensitivity in P2P accommodation as consumers sought accommodation options that offers a greater value for money. Amaro et al. (2019) argue the foregoing contentions by asserting that economic benefits are perceived to be less important especially for millennial consumers. The authors added to further examine the matter and track consumer behavior over time to verify extant claims.

Meanwhile, P2P accommodation and the sharing economy as a whole are commonly recognized for their implications towards environmental sustainability (Heinrichs, 2013; Voytenko Palgan et al., 2017). This is along the lines of efficiently utilizing idle resources through access-based consumption in digital platforms (Botsman \& Rogers, 2010). Hence, it is presumed to mitigate unsustainable consumption practices, thereby, help obviate the eventualities of resource depletion associated with production of new goods (Pouri \& Hilty, 2018). PriceWaterhouseCoopers (2015b) reveal that a large share of US consumers perceived the positive environmental implications of the sharing economy pertaining to waste reduction. Bakker \& Twining-Ward (2018) point out that utilizing existing structures over building new ones for accommodation rentals contributes to environmental sustainability. Meanwhile, 
Hamari et al. (2016), Möhlmann (2015), and Tussyadiah (2015) highlight that significant role of environmental sustainability as one of the main drivers of collaborative consumption among consumers. Kim \& Jin (2020) likewise assert that as consumers manifest great concern for the environment, the more they will favor collaborative consumption. Thus, Toni et al. (2018) point out that consumers usage and sustainable behaviors can be further encouraged if P2P providers promote their disposition on environmental sustainability. In contrary to the prior claims, Garau-Vadell et al. (2019) reveal the insignificance of environmental perception in shaping Spanish residents to support P2P accommodation. Sung et al. (2018) also assert that sustainability solely matters for accommodation providers and not to accommodation seekers.

Given the information sought in the literature and the importance of perception in consumers purchase decision, therefore, the study carry-out an exploratory investigation to answer the following research questions:

- Do familiarity, usage and overall perception towards P2P accommodation differ among tourists in the selected countries?

- Do economic and environmental sustainability perceptions towards P2P accommodation differ among tourist nationalities? Are these associated to their overall positive perceptions of P2P accommodation services?

- Are socio-demographic variables associated with consumers perception towards P2P accommodation?

\section{METHODOLOGY}

The study implemented a web-based survey via Google forms platform between January and March 2020. The questionnaire mainly included items that capture the tourists' familiarity, past usage and perceptions towards P2P accommodation services. The assessment on the past usage of P2P accommodation services was stretched to cover for over the past 6 months as the travelling frequency of respondents cannot be initially ascertained. It is presumed that the 6 months recall question is enough to capture the usage for both frequent and non-frequent travelers or tourists. And in view of the substantial relationship of past behavior and future behavior (Ouellette \& Wood, 1998), operationalizing past usage was deemed significant for inclusion in the study. Meanwhile, it should be noted that in some time during the conduct of the survey, some travel restrictions were enforced due to Covid-19 related pronouncements. Thus, to capture the respondents' usage in the "normal" times, the recall question for usage (i.e. usage for the past 6 months) was deemed suitable. Familiarity and past usage were measured dichotomously (i.e. Yes-No), while perceptions were measured using a 7-point Likert scale. English is considered an official language in the Philippines and India, thus, only the questionnaire administered to Thai respondents underwent translation procedures. The questionnaire was pre-tested to about 20 respondents after its initial development. After several modifications, distribution of the web survey link was carried out in social networking platforms following a convenience sampling procedure. The selection of respondents was based upon the considerations of accessibility, proximity, and availability. The research likewise pursued a collaboration with doctoral students residing on each of the selected countries. They were mainly instructed to disseminate the link of the survey questionnaire to their networks in their respective countries and supervise the data collection process. A total of 313 valid responses were collected across countries. For data analysis, descriptive analysis and nonparametric tests (i.e. Chi square statistics, Kruskal-Wallis $\mathrm{H}$ test, Mann-Whitney $\mathrm{U}$ test, Spearman rho) were operationalized using IBM SPSS version 23. The summary of demographic profile of respondents is presented in Table 1. 


\section{RESULTS AND DISCUSSION}

This section primarily presents the survey findings with emphasis on the differences in familiarity, usage, perceived economic benefits, perceived environmental sustainability and ultimately the overall perception towards P2P accommodation among tourists from the selected emerging countries.

\subsection{Familiarity, Usage and Overall Perception towards P2P Accommodation}

The analysis shows that familiarity towards P2P accommodation services significantly differs among tourist nationalities $\left(x^{2}=20.187, p=0.000\right)$. As reflected in Fig.1a, there are more respondents in India (75.2\%) and the Philippines (62.8\%) that are familiar with P2P accommodation than Thailand (44.4\%). However, difference in usage is not significant across nationalities $\left(x^{2}=5.859, p>0.05\right)$. Less than half of the respondents in each country have expressed their usage over the past 6 months. Among them, Indians, Thai, and Filipinos mostly used OYO rooms (45.3\%), Booking.com (44.4\%), and Airbnb (24.3\%), respectively (Fig.1b). This reveals that Airbnb may not the best choice in all selected tourist nationalities despite its global reach and popularity. Noticeably, commonly used accommodation platforms in India and Thailand do not purely provide P2P accommodation as they also offer accommodations from leased or franchised hotels as well. Overall perception towards P2P accommodation seems to be positive across nationalities $\left(x^{2}=3.663, p>0.05\right)$ (Fig. 2a). The analysis also reveals that users have more positive perception than non-users $(U=6875, p=0.000)$ (Fig. $2 \mathrm{~b})$.

Tab. 1 Demographic profile of respondents

\begin{tabular}{lccc}
\hline \multirow{2}{*}{ Demographic Variable } & \multicolumn{3}{c}{ Country } \\
\cline { 2 - 5 } & India $(\mathrm{n}=101)$ & Thailand $(\mathrm{n}=99)$ & Philippines $(\mathrm{n}=113)$ \\
\hline Age (Mean) & 22.59 & 26.52 & 25.30 \\
\hline $26-25$ & 84 & 60 & 69 \\
\hline $35-44$ & 16 & 22 & 37 \\
\hline 45 and above & 1 & 14 & 1 \\
\hline Educational Attainment & 0 & 3 & 90 \\
\hline Bachelor's degree & 64 & & 3 \\
Doctoral Degree & 1 & 78 & 20 \\
Master's degree & 36 & 3 & 32 \\
\hline Gender & & 18 & 70 \\
\hline Male & 54 & & 11 \\
Female & 46 & 30 & 1 \\
LGBGTQ+ & 1 & 59 & 14 \\
\hline Marital Status & 1 & 10 & 98 \\
\hline Divorced & 7 & 13 & \\
Married & 93 & 85 & \\
Single & & & \\
\hline
\end{tabular}




\begin{tabular}{lccc}
\hline Occupation & & & \\
\hline Employed & 11 & 29 & 74 \\
Self Employed & 6 & 9 & 4 \\
Student & 79 & 60 & 31 \\
Unemployed & 5 & 1 & 4 \\
\hline
\end{tabular}

Source: own survey findings, January-March 2020

Fig. 1 P2P accommodation familiarity and usage (a) and platform used (b)

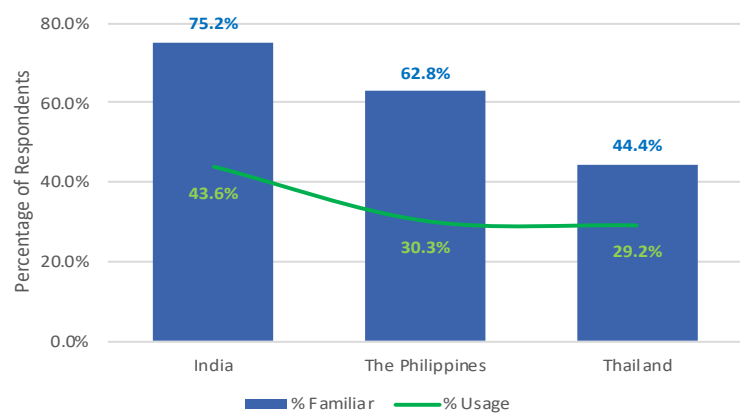

(a)

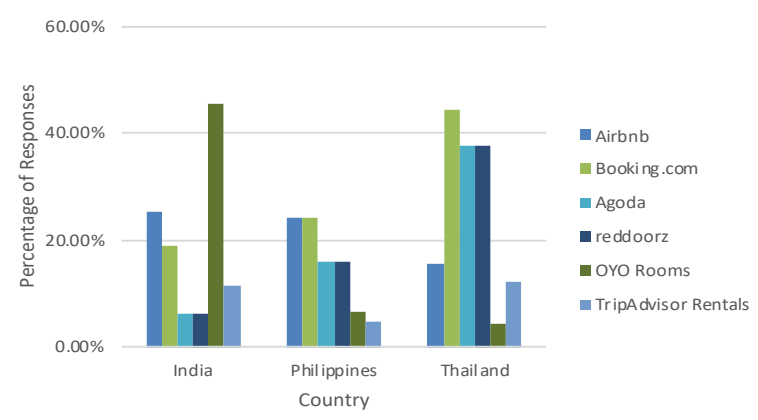

(b)

Source: own survey findings, Data Collection: January-March 2020

Fig. 2 Overall perception towards P2P accommodation per country (a) and usage (b)

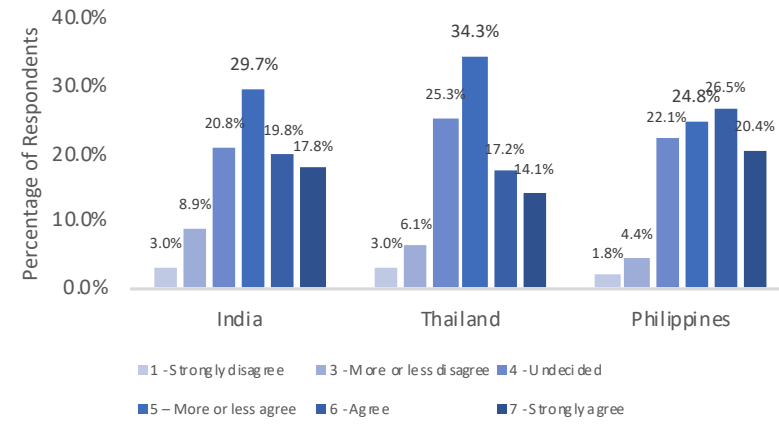

(a)

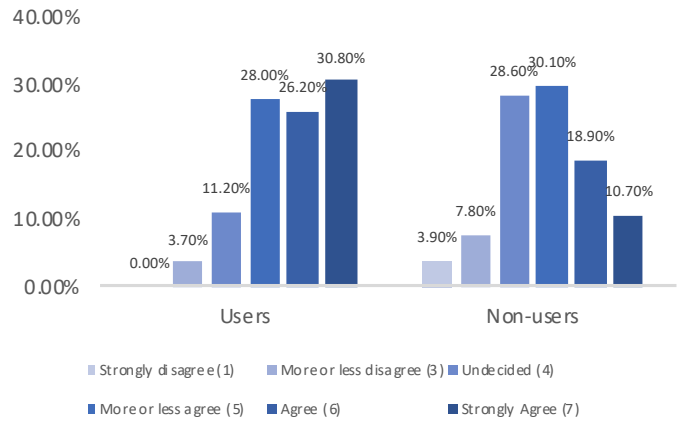

(b)

Source: own survey findings, Data Collection: January-March 2020

Moreover, among demographic variables, findings show that only age demonstrates a significant difference in terms of familiarity $(U=9,015, p=0.001)$, usage $(U=8,779, p=0.003)$ and overall perception $(U=8,942.5, p=0.026)$ towards P2P accommodation. Mean ranks show that older respondents are more familiar, are users and have positive perceptions towards P2P accommodation (Tab. 2). Educational attainment also turns out to be significantly different between familiar and non-familiar tourists $(U=9,351.5, p=0.000)$. As reflected by mean rank values, it indicates that those who are familiar with P2P accommodation have higher educational attainment. Although, correlation among age and education towards overall perceptions are not found to be significant. 
Tab. 2 Mann-Whitney's test mean rank results on age, education, familiarity, usage, and perception

\begin{tabular}{|c|c|c|c|c|}
\hline \multirow{9}{*}{ Age } & Familiarity & Mean Rank & Mann-Whitney U & $\mathrm{p}$-value \\
\hline & Yes & 170.80 & \multirow{2}{*}{9015.000} & \multirow{2}{*}{0.001} \\
\hline & No & 135.39 & & \\
\hline & \multicolumn{2}{|l|}{ Usage } & & \\
\hline & Yes & 177.95 & \multirow{2}{*}{8779.000} & \multirow{2}{*}{0.003} \\
\hline & No & 146.12 & & \\
\hline & \multicolumn{2}{|l|}{ Perception } & & \\
\hline & Positive & 164.71 & \multirow{2}{*}{8942.500} & \multirow{2}{*}{0.026} \\
\hline & Negative & 140.33 & & \\
\hline \multirow{3}{*}{ Education } & Familiarity & & & \\
\hline & Yes & 169.04 & \multirow{2}{*}{9351.500} & \multirow{2}{*}{0.000} \\
\hline & No & 138.15 & & \\
\hline
\end{tabular}

Source: Own processing in IBM SPSS v23 Data Collection: January-March 2020

\subsection{Economic and sustainability perceptions towards P2P accommodation}

P2P accommodation is better known for its economic advantage over traditional accommodation alternatives. Extant studies supported this claim by specifying its relationship with consumers' choices, intentions, and actual behavior in using the service. Thus, the study investigates whether tourists from selected emerging countries have perceived these presumed economic benefits. Findings reveal that most respondent's express affirmation on the affordability of P2P accommodation (Fig. 3a). However, the analysis reveals a significant difference in perception among nationalities $(H=7.278, p=0.026)$. Scrutinizing this difference, pairwise comparisons between countries indicate that respondents in Thailand and India differ on economic perceptions $(t=32.984, p=0.024)$. This means that Indian tourists' perception on the economic benefits of P2P accommodation evidently exceeds than Thai tourists. On another note, sustainability perception on P2P accommodation remains mostly positive across nationalities. Fig. $3 \mathrm{~b}$ shows that a considerable percentage of respondent's express agreement on its environmental implications specifically on its contributory effects in cutting-back the consumption of natural resources. These affirmations are also supplemented by the mean and median figures. However, evidence suggest that these perceptions do not significantly vary across nationalities $(H=0.522, p>0.05)$.

Meanwhile, Tab. 3 displays the Spearman rho correlation results between perceived economic benefits and perceived environmental sustainability towards overall perception amongst nationalities. The results signify that economic and sustainability perception is significantly correlated with overall perception of tourists towards P2P accommodation. This implies that overall perception increases as economic and sustainability perception also increases. By carefully examining the strength of correlation on the basis of Hinkle \& Wiersma (2009) guidelines, it turns out that the correlation is moderate between economic perception and overall perception for Thailand and Philippines. The same is also observed for Thailand regarding sustainability perception and overall perception. Nevertheless, despite these weak to moderate correlation, the findings put forward an evident manifestation that the economic value and sustainability implications of P2P accommodation are also diffused even to tourists 
on the selected emerging countries. This further endorses that these aforementioned perceptions may shape tourists' appreciation towards P2P accommodation services.

Furthermore, the association of economic and sustainability perceptions across sociodemographic characteristics was examined. Results of the analysis indicate that only age and environmental sustainability have a significant negative association (rho $=-0.117, p=0.039$ ). This finding implies that as age increases, the level of perceived environmental sustainability decreases. In other words, young people perceived a higher level of environmental sustainability than the older ones.

\section{Fig. 3 Economic (a) and sustainability (b) perceptions towards P2P accommodation}

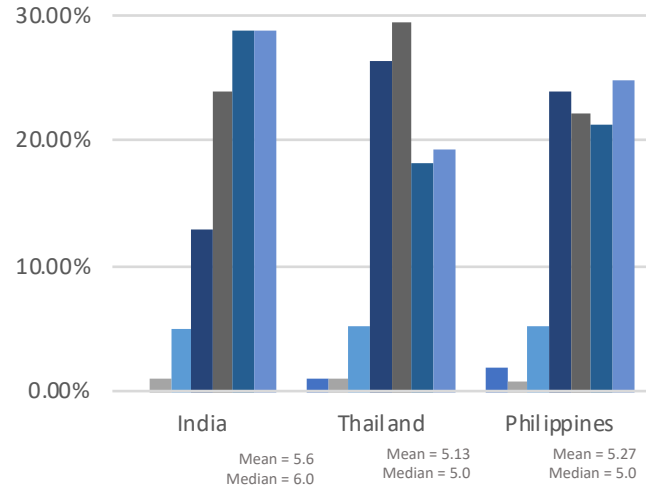

(a) Economic perceptions

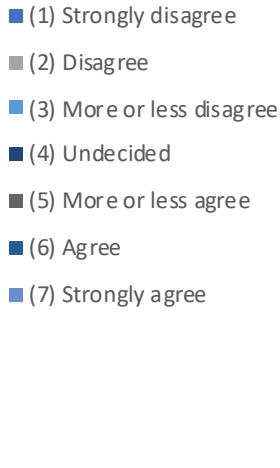

trongly disagre

- (3) More or less disagree

or less agre

(6) Agree

- (7) Strongly agree

Source: Own survey findings, Data Collection: January-March 2020

Table 3. Correlation of economic benefits and environmental sustainability towards overall perception

\begin{tabular}{lllll}
\hline \multirow{2}{*}{ Country } & \multicolumn{2}{l}{$\begin{array}{l}\text { Economic benefits } \rightarrow \\
\text { Overall perception }\end{array}$} & \multicolumn{2}{l}{$\begin{array}{l}\text { Environmental sustainability } \rightarrow \\
\text { Overall Perception }\end{array}$} \\
\cline { 2 - 5 } & Coefficient & Sig. (2-tailed) & Coefficient & Sig. (2-tailed) \\
\hline India & $.399^{* *}$ & 0.000 & $.365^{* *}$ & 0.000 \\
\hline Thailand & $.465^{* *}$ & 0.000 & $.432^{* *}$ & 0.000 \\
\hline Philippines & $.456^{* *}$ & 0.000 & $.313^{* *}$ & 0.001 \\
\hline
\end{tabular}

** Correlation is significant at the 0.01 level (2-tailed)

Source: own processing in IBM SPSS v23

\section{CONCLUSION}

The exploratory investigation on familiarity, usage, and perceptions towards P2P accommodation among tourists from the selected emerging countries in Asia seems to be promising based on the study findings. The study underscores the following points to suffice the research questions set in the current investigation:

- Evidence shows that familiarity is relatively high among tourists from India and Philippines. Across nationalities, usage remains sluggish over the past six months even 
prior the pronouncement of the Covid-19 pandemic in the first quarter of 2020 . Meanwhile, respondents' overall perception towards the service remains positive across nationalities. It is revealed that there is no significant difference on the past usage and the overall positive perception towards P2P accommodation services across nationalities. In spite of these, it is argued that the concept of P2P accommodation has already diffused over the emerging markets as an alternative form of lodging service. Hybrid platform providers offering both hotel and P2P accommodation options are found to be dominating despite the popularity of Airbnb from the industry perspective. Moreover, as existing studies commonly associate P2P accommodation with Airbnb, the study offers a fresh insight to researchers to carry-out further investigations on the dynamics of hybrid platforms together with consumer behavior to grasp an all-inclusive knowledge to contribute to the literature.

- $\quad$ P2P accommodation and the sharing economy in general are notably positioned in the market over its economic advantages and sustainability implications. Evidence shows that these are grasped favorably by all tourists from the selected emerging countries. No significant differences were found on the economic and sustainability perceptions across nationalities. Furthermore, the analysis indicates that the aforementioned perceptions are found to be significantly correlated to their overall positive perception of P2P accommodation services. These affirmative perceptions may drive the actual usage among tourists on the service across nationalities. Besides, extant evidences claim the significance of environmental sustainability perceptions (Hamari et al., 2016; Möhlmann, 2015; Tussyadiah, 2015) and economic incentives (Guttentag et al., 2018; Möhlmann, 2015; Tussyadiah, 2015) in driving consumers to use P2P services, collaborative consumption and the sharing economy in general. Therefore, disclosing these popular notions to existing and prospective consumers through various media channels may enhance their perception and consequently their actual usage as well. Nevertheless, future investigation is required to examine and establish the causality between the aforesaid perceptions and actual consumer usage especially the incidence of Covid19 pandemic.

- Age and educational attainment of tourists appear to be associated with their overall positive perception on $\mathrm{P} 2 \mathrm{P}$ accommodation services. This roughly conforms to existing evidence in the literature that P2P services highly attract young (Bakker \& TwiningWard, 2018; Hwang \& Griffiths, 2017) and educated individuals (Buda et al., 2019; Šiuškaite et al., 2019). Paying attention to consumer education and generation is crucial in designing strategies to expand customer base. Special focus should be given to the educated and young adults (i.e. ages 18-35 years) as they are more fascinated towards the service. Distinctively, young consumers seem to exceedingly perceive the environmental implications of P2P accommodation than the older ones.

Nonetheless, due to the exploratory nature of the study, it is necessary to demonstrate caution in generalizing the reported findings. It is advised to improve the sample characteristics and/or sample representativeness in future studies. Likewise, further studies should explore and examine other influences that drive and/or restrain the use of P2P accommodation. A more comprehensive investigation with a more robust approach needs to be carried-out to detail and uncover the specificities of tourists' consumption behavior towards P2P accommodation. Lastly, P2P accommodation and the global tourism industry in general are adversely hit by the COVID19 pandemic. This may also have altered travelers' consumption patterns. As states institute measures to reboot the industry, further research is necessary to understand the particularities of residents' accommodation booking decisions and the interplay of hygiene and sanitation factors in the post-pandemic scenario.

All in all, the study offers initial insights on the P2P accommodation phenomenon on the selected tourism hubs in the emerging countries of Asia. The study found support to economic 
benefits and environmental sustainability as popularly claimed hallmarks of P2P accommodation which is within the realm of the sharing economy. The promising uptake towards P2P accommodation services among tourists across nationalities pose relevant implications to service and P2P platform providers locally and abroad. Evidence shows that P2P accommodation service seems to become a competitive alternative for services offered by traditional accommodation providers (i.e. hotels). This is owing to its affordability as compared to traditional counterparts. Moreover, as it is framed as an environmentally sustainable offering, conscious individuals may likewise be attracted to use the service. Thus, to further expand the usage of consumers locally and abroad, there is a need to further promote its economic and sustainability nuances in various media channels. Meanwhile, the boost in tourism across the selected countries implies the need for additional and more competitive accommodation services. Foreign P2P platforms (firms) can take advantage of this profound opportunity by providing the platforms that enable peer-to-peer sharing of accommodation. Concurrently, this will offer more income opportunities in the emerging countries, especially for people who possess and are willing to share-out their extra living spaces to others.

\section{ACKNOWLEDGEMENT}

The authors are thankful to the Internal Grant Agency of FaME TBU in Zlín No. IGA/FaME/2021/003 (Consumer behaviour and Performance management of firms in a competitive digital world) for financial support to carry out this research.

\section{REFERENCES}

Airbnb. (2020). Airbnb Fast Facts. Airbnb News Room. Retrieved 23 July 2020, from https://news.airbnb.com/fast-facts/

Amaro, S., Andreu, L., \& Huang, S. (2019). Millenials' intentions to book on Airbnb. Current Issues in Tourism, 22(18), 2284-2298. https://doi.org/10.1080/13683500.2018.1448368

Bakker, M., \& Twining-Ward, L. (2018). Tourism and the Sharing Economy: Policy and Potential of Sustainable Peer-to-Peer Accommodation. The World Bank Group. Retrieved 8 June 2020, from http://documents.worldbank.org/curated/en/161471537537641836/pdf/130054REVISED-Tourism-and-the-Sharing-Economy-PDF.pdf

Belarmino, A., \& Koh, Y. (2020). A critical review of research regarding peer-to-peer accommodations. International Journal of Hospitality Management, 84, 102315. https://doi.org/10.1016/j.ijhm.2019.05.011

Belk, R. (2010). Sharing: Table 1. Journal of Consumer Research, 36(5), 715-734. https://doi.org/10.1086/612649

Belk, R. (2014). You are what you can access: Sharing and collaborative consumption online. Journal of Business Research, 678), 1595-1600. https://doi.org/10.1016/j.jbusres.2013.10.001

Botsman, R., \& Rogers, R. (2010). What's mine is yours: The rise of collaborative consumption. Harper Business.

Buda, G., Pethes, B., \& Lehota, J. (2019). Dominant Consumer Attitudes in the Sharing Economy-A Representative Study in Hungary. Resources, 9(1), 1. https://doi.org/10.3390/resources9010001

Chen, C.-C., \& Chang, Y.-C. (2018). What drives purchase intention on Airbnb? Perspectives of consumer reviews, information quality, and media richness. Telematics and Informatics, 35(5), 1512-1523. https://doi.org/10.1016/j.tele.2018.03.019 
Codagnone, C., \& Martens, B. (2016). Scoping the Sharing Economy: Origins, Definitions, Impact and Regulatory Issues. SSRN Electronic Journal. https://doi.org/10.2139/ssrn.2783662

Frenken, K., Meelen, T., Arets, M., \& van de Glind, P. (2014, December 9). Smarter regulation for the sharing economy. The Guardian. Retrieved 18 March 2020, from https://www.theguardian.com/science/political-science/2015/may/20/smarter-regulation-forthe-sharing-economy

Garau-Vadell, J. B., Gutiérrez-Taño, D., \& Díaz-Armas, R. (2019). Residents' Support for P2P Accommodation in Mass Tourism Destinations. Journal of Travel Research, 58(4), 549-565. https://doi.org/10.1177/0047287518767067

Guttentag, D., Smith, S., Potwarka, L., \& Havitz, M. (2018). Why Tourists Choose Airbnb: A Motivation-Based Segmentation Study. Journal of Travel Research, 57(3), 342-359. https://doi.org/10.1177/0047287517696980

Habibi, M. R., Davidson, A., \& Laroche, M. (2017). What managers should know about the sharing economy. Business Horizons, 60(1), 113-121. https://doi.org/10.1016/j.bushor.2016.09.007

Hamari, J., Sjöklint, M., \& Ukkonen, A. (2016). The sharing economy: Why people participate in collaborative consumption. Journal of the Association for Information Science and Technology, 679), 2047-2059. https://doi.org/10.1002/asi.23552

Heinrichs, H. (2013). Sharing economy: A potential new pathway to sustainability. Ecological Perspectives for Science. Retrieved 20 July 2020, from https://www.ingentaconnect.com/contentone/oekom/gaia/2013/00000022/00000004/art000 05 ?crawler $=$ true

Hinkle, D. E., \& Wiersma, W. (2009). Applied Statistics for Behavioral Sciences, International 5th Edition. Cengage Learning. Inc., Boston.

Hossain, M. (2020). Sharing economy: A comprehensive literature review. International Journal of Hospitality Management, 87, 102470. https://doi.org/10.1016/j.ijhm.2020.102470

Hwang, J., \& Griffiths, M. A. (2017). Share more, drive less: Millennials value perception and behavioral intent in using collaborative consumption services. The Journal of Consumer Marketing; Santa Barbara, 34(2), 132-146. http://dx.doi.org/10.1108/JCM-10-2015-1560

Kim, N. L., \& Jin, B. E. (2020). Why buy new when one can share? Exploring collaborative consumption motivations for consumer goods. International Journal of Consumer Studies, 44(2), 122-130. https://doi.org/10.1111/ijcs.12551

Mahadevan, R. (2018). Examination of motivations and attitudes of peer-to-peer users in the accommodation sharing economy. Journal of Hospitality Marketing \& Management, 276), 679-692. https://doi.org/10.1080/19368623.2018.1431994

Medina-Hernandez, V. C., Marine-Roig, E., \& Ferrer-Rosell, B. (2020). Accommodation sharing: A look beyond Airbnb's literature. International Journal of Culture, Tourism and Hospitality Research, 14(1), 21-33. https://doi.org/10.1108/IJCTHR-07-2019-0130

Möhlmann, M. (2015). Collaborative consumption: Determinants of satisfaction and the likelihood of using a sharing economy option again: Collaborative consumption-determinants of satisfaction and the likelihood of using a sharing economy option again. Journal of Consumer Behaviour, 14(3), 193-207. https://doi.org/10.1002/cb.1512

Nam, C., Dong, H., \& Lee, Y.-A. (2017). Factors influencing consumers' purchase intention of green sportswear. Fashion and Textiles, 4(1), 2. https://doi.org/10.1186/s40691-017-0091-3

Ouellette, J. A., \& Wood, W. (1998). Habit and intention in everyday life: The multiple processes by which past behavior predicts future behavior. Psychological Bulletin, 124(1), 54 74. https://doi.org/10.1037/0033-2909.124.1.54 
Pappas, N. (2017). The complexity of purchasing intentions in peer-to-peer accommodation. International Journal of Contemporary Hospitality Management, 29(9), 2302-2321. https://doi.org/10.1108/IJCHM-08-2016-0429

Pouri, M. J., \& Hilty, L. M. (2018). Conceptualizing the Digital Sharing Economy in the Context of Sustainability. Sustainability, 10(12), 4453. https://doi.org/10.3390/su10124453

Prayag, G., \& Ozanne, L. K. (2018). A systematic review of peer-to-peer (P2P) accommodation sharing research from 2010 to 2016: Progress and prospects from the multi-level perspective. Journal of Hospitality Marketing \& Management, 276), 649-678. https://doi.org/10.1080/19368623.2018.1429977

PriceWaterhouseCoopers. (2015a). Sharing or paring? Growth of the sharing economy (p. 32). Retrieved $12 \quad$ February 2020, from https://www.pwc.com/hu/en/kiadvanyok/assets/pdf/sharing-economy-en.pdf

PriceWaterhouseCoopers. (2015b). The Sharing Economy: Consumer Intelligence Series (p. 30). $\quad$ Retrieved 12 February 2020, from https://www.pwc.fr/fr/assets/files/pdf/2015/05/pwc_etude_sharing_economy.pdf

Retamal, M., \& Dominish, E. (2017). The Sharing Economy in Developing Countries. Institute for Sustainable Futures at the University of Technology Sydney (UTS) for Tearfund UK. Retrieved $10 \quad$ June 2020, from https://learn.tearfund.org/ /media/files/tilz/circular_economy/2017-tearfund-the-sharingeconomy-in-developing-countries-en.pdf?la=en

Šiuškaitè, D., Pilinkienè, V., \& Žvirdauskas, D. (2019). The Conceptualization of the Sharing Economy as a Business Model. Engineering Economics, 30(3), 373-381. https://doi.org/10.5755/j01.ee.30.3.21253

Sung, E., Kim, H., \& Lee, D. (2018). Why Do People Consume and Provide Sharing Economy Accommodation?-A Sustainability Perspective. Sustainability, 10(6), 2072. https://doi.org/10.3390/su10062072

Tussyadiah, I. P. (2015). An Exploratory Study on Drivers and Deterrents of Collaborative Consumption in Travel. In I. Tussyadiah \& A. Inversini (Eds.), Information and Communication Technologies in Tourism 2015 (pp. 817-830). Springer International Publishing. https://doi.org/10.1007/978-3-319-14343-9_59

Tussyadiah, I. P., \& Park, S. (2018). When guests trust hosts for their words: Host description and trust in sharing economy. Tourism Management, 67, 261-272. https://doi.org/10.1016/j.tourman.2018.02.002

Voytenko Palgan, Y., Zvolska, L., \& Mont, O. (2017). Sustainability framings of accommodation sharing. Environmental Innovation and Societal Transitions, 23, 70-83. https://doi.org/10.1016/j.eist.2016.12.002

Wee, C. S., Ariff, M. S. B., Zakuan, N., Tajudin, M. N. M., Ismail, K., Ishak, N., \& Haji, L. T. (2014). Consumers Perception, Purchase Intention and Actual Purchase Behavior of Organic Food Products. Review of Integrative Business and Economics Research, 3, 20.

Yan, R., Zhang, K. Z. K., \& Yu, Y. (2019). Switching from hotels to peer-to-peer accommodation: An empirical study. Information Technology \& People, 32(6), 1657-1678. https://doi.org/10.1108/ITP-12-2017-0444

Young, C. A., Corsun, D. L., \& Xie, K. L. (2017). Travelers' preferences for peer-to-peer (P2P) accommodations and hotels. International Journal of Culture, Tourism and Hospitality Research, 11(4), 465-482. https://doi.org/10.1108/IJCTHR-09-2016-0093 